\title{
Two-Dimensional Simulation of Barley Growth and Yield Using a Model Integrated with Remote-Controlled Aerial Imagery
}

\author{
Ashifur Rahman Shawon ${ }^{1,+}\left(\mathbb{D}\right.$, Jonghan Ko ${ }^{1, *} \mathbb{\infty}$, Seungtaek Jeong ${ }^{1}{ }^{(D}$, Taehwan Shin ${ }^{1}$, \\ Kyung Do Lee ${ }^{2}$ and Sang In Shim ${ }^{3}$ \\ 1 Department of Applied Plant Science, Chonnam National University, Gwangju 61186, Korea; \\ ashifur.shawon@julius-kuehn.de (A.R.S.); stjeong@kari.re.kr (S.J.); shintaehwan6465@gmail.com (T.S.) \\ 2 Department of Agricultural Environment, National Institute of Agricultural Science, Wanju-gun 55365, \\ Korea; kdlee11@korea.kr \\ 3 Department of Agricultural Science, Gyeongsang National University, Jinju 52828, Korea; sishim@gsnu.ac.kr \\ * Correspondence: jonghan.ko@jnu.ac.kr; Tel.: +82-62-530-2053 \\ + Current affiliation: Federal Research Center for Cultivated Plants, Institute for Strategies and Technology \\ Assessment, 14532 Kleinmachnow, Germany.
}

Received: 27 September 2020; Accepted: 12 November 2020; Published: 16 November 2020

\begin{abstract}
It is important to be able to predict the yield and monitor the growth conditions of crops in the field to increase productivity. One way to assess field-based geospatial crop productivity is by integrating a crop model with a remote-controlled aerial system (RAS). The objective of this study was to simulate spatiotemporal barley growth and yield based on the development of a crop-modeling system integrated with RAS-based remote sensing images. We performed field experiments to obtain ground truth data and RAS images of crop growth conditions and yields at Chonnam National University (CNU), Gwangju, South Korea in 2018, and at Gyeongsang National University (GNU), Jinju, South Gyeongsang, South Korea in 2018 and 2019. In model calibration, there was no significant difference $(p=0.12)$ between the simulated barley yields and measured yields, based on a two-sample $t$-test at CNU in 2018. In model validation, there was no significant difference between simulated yields and measured yields at $p=0.98$ and 0.76 , according to two-sample $t$-tests at GNU in 2018 and 2019, respectively. The remote sensing-integrated crop model accurately reproduced geospatial variations in barley yield and growth variables. The results demonstrate that the crop modeling approach is useful for monitoring at-field barley conditions.
\end{abstract}

Keywords: barley; crop model; integration; RAS; remote sensing; yield

\section{Introduction}

Barley (Hordeum vulgare), a major cereal grain grown in temperate climates globally, is an important staple crop in the Korean peninsula and worldwide. It is used as animal fodder, a fermentable source material for beer, and a constituent of various health foods [1]. To increase productivity through integrated crop management practices, it is crucial to monitor growth conditions and to have an early estimation of barley yield. Crop modeling and remote sensing (RS) techniques are typical approaches to estimate crop yield and monitor growth [2]. Process-based crop models are useful for simulating seasonal patterns of crop growth and predicting yield, while empirical models can simulate certain environmental conditions for growth or crop yield [3]. Remote sensing is useful for surveying geospatial variability in crop growth conditions over the growing season [4]. Each technique for crop modeling and remote sensing has certain advantages, e.g., crop models are able to simulate growth sequentially, while RS can monitor geospatial variations in crop conditions dependably $[5,6]$. 
Process-based crop growth models include a set of equations that can define crop growth and development on a continuous scale up to harvest [3]. The parameters in a process-based mathematical model are highly dependent on the ecophysiological responses of the canopy growth that is specific to different cultivars [7]. Dependable simulation using a crop model requires a large number of inputs, including specific crop growth parameters and other variables related to soil and weather [8]. Biological system modelers use parameters to simplify the model and estimation of the crop growth specific variables, which generally makes things more difficult [9]. Crop models often require some specific parameters to model the correct growth response, which can limit the use of the model elsewhere. As a result, crop growth simulation models frequently fail to estimate the regional or geographical variations in crop yield with reasonable accuracy because they lack appropriate spatial and temporal information about canopy growth [10] and accurate input data [11].

Crop growth and yield can also be observed using the empirical relationship between biomass and remotely sensed information derived from a remote-controlled aerial vehicle (RAV) or a satellite [12,13]. Many studies have investigated the relationship between crop yield and vegetation indices for assessing crop growth conditions and phenology [14,15]. For practical reasons, these types of (semi-) empirical regression are only suitable for evaluating growth conditions in a specific region. Moreover, they ignore or cannot explain the interaction of radiation intercepted within the vegetation canopies [12]. In addition, most platforms, either RAVs or satellites, are unable to provide the required information continuously, either because of limited revisit periods to the fields of interest or adverse environmental conditions [6,11].

The integration of RS information into a crop model may reinforce the advantages of RS and crop modeling as well as compensate for the limitations of each approach, allowing for accurate geospatial crop productivity monitoring and yield forecasting at different scales in croplands $[2,16]$. Studies have proved the effectiveness of combining crop modeling and RS approaches $[2,17,18]$. One important advance is the gramineous crop model, GRAMI, which is able to use remote sensing data [19]. GRAMI $[9,20]$ is a simulation model that uses simple crop parameters, weather variables, and RS information from any platform to simulate grain crop growth and yield. This model was expanded to simulate other crops such as cotton [21,22], soybean [23], and paddy rice [5,16,24,25] at different scales from fields to regions. The current version of the model has been renamed as the remote sensing-integrated crop model (RSCM) in order to incorporate the model updates mentioned above and for future applications for other crops [23].

We assumed that the RSCM would be applicable for the geospatial simulation of crops at a field scale because the RSCM system could use RAS-based RS images for the geospatial reproduction of crop growth conditions and productivity [16]. Moreover, there has been growing interest in utilizing RAS for various agricultural business activities, e.g., field-based crop monitoring and management [26-28]. Therefore, the objective of this study was to extend the RSCM for the geospatial simulation of barley growth and yield at a field scale based on parameterizing the model using ground- and RAS-based RS information.

\section{Materials and Methods}

\subsection{Site Description}

Field experiments were performed to evaluate the RSCM system for the simulation of barley growth and yield at two locations, namely, Gwangju and Jinju in South Korea, during the 2018 and 2019 growing seasons. The experiment in Gwangju was carried out to estimate model parameters and obtain a dataset to calibrate the modeling system at Chonnam National University (CNU) $\left(35^{\circ} 10^{\prime}\right.$ $\mathrm{N}, 126^{\circ} 53^{\prime} \mathrm{E} ; 33 \mathrm{~m}$ ) in the 2018 season. The other field experimental data were collected for model validation at Gyeongsang National University (GNU) $\left(35^{\circ} 8^{\prime} \mathrm{N}, 128^{\circ} 5^{\prime} \mathrm{E} ; 33 \mathrm{~m}\right)$, Jinju in the 2018 and 2019 seasons. These study sites have a typical East Asian monsoon climate. The mean annual temperatures have been 13.8 and $13.1^{\circ} \mathrm{C}$ and the average yearly precipitation recorded is 1391 and 1513 
$\mathrm{mm}$ in Gwangju and Jinju, respectively, for over the past 30 years according to the Korea Meteorological Administration (https://www.kma.go.kr/eng/). Most of the precipitation (about 60\%) occurs during the summer monsoon season (July-August). At CNU, the topmost soil layer $(0-30 \mathrm{~cm})$ is categorized as loam (sand $43.1 \%$, silt $30.9 \%$, clay $26.0 \%$ ), with a $\mathrm{pH}\left(\mathrm{H}_{2} \mathrm{O}\right) 6.5$, organic carbon content (OCC) of $12.3 \mathrm{~g} \mathrm{C} \mathrm{kg}^{-1}$, available phosphorus (P) of $131 \mathrm{mg} \mathrm{P}_{2} \mathrm{O}_{5} \mathrm{~kg}^{-1}$, cation exchange capacity (CEC) (Ca ${ }^{+2}$, $\mathrm{K}^{+}$, and $\mathrm{Mg}^{2+}$ ) of $14.4 \mathrm{cmol}_{\mathrm{C}} \mathrm{kg}^{-1}$, and total nitrogen before fertilization (TN) of $1.0 \mathrm{~g} \mathrm{~N} \mathrm{~kg}^{-1}$ according to the National Institute of Agricultural Sciences (www.naas.go.kr/english/). At GNU, the topmost soil layer $(0-20 \mathrm{~cm})$ is categorized as sandy loam (sand $71.4 \%$, silt $18.8 \%$, clay $9.7 \%$ ), with a pH $\left(\mathrm{H}_{2} \mathrm{O}\right) 5.9$, OCC of $8.6 \mathrm{~g} \mathrm{C} \mathrm{kg}^{-1}$, P of $185 \mathrm{mg} \mathrm{P}_{2} \mathrm{O}_{5} \mathrm{~kg}^{-1}, \mathrm{CEC}\left(\mathrm{Ca}^{+2}, \mathrm{~K}^{+}\right.$, and $\left.\mathrm{Mg}^{2+}\right)$ of $6.3 \mathrm{cmol}_{\mathrm{C}} \mathrm{kg}^{-1}$, and TN of $0.053 \mathrm{~g} \mathrm{~N} \mathrm{~kg}^{-1}$.

\subsection{Field Experiment}

Four barley cultivars (Black, Heenchal, Hopum, and Saechal) were sown on 7 November 2017 and harvested on 20 June 2018 in an area of $\approx 206.4 \mathrm{~m}^{2}$ at CNU. At GNU, the barley cultivar, Heenchal, was sown on 9 February and 30 October 2018 and 18 February 2019 and harvested 25 June 2018 and 10 June 2019, respectively, in an area of $\approx 262.5 \mathrm{~m}^{2}$. Detailed information on the cultivars can be found at the National Institute of Crop Science website (www.nics.go.kr/english/). The experimental blocks at both CNU and GNU were arranged in a randomized complete block design with three replications. The kernels were sown using a mechanical seed drilling device in a row spacing of $20 \mathrm{~cm}$ and a hill-to-hill spacing of $10 \mathrm{~cm}$. Nitrogen (N) in $\mathrm{CO}\left(\mathrm{NH}_{2}\right)_{2}$, phosphorus (P) in $\mathrm{CaOBMgOP}{ }_{2} \mathrm{O}_{2} \mathrm{NSO}_{2}-\mathrm{F}$, and potassium $(\mathrm{K})$ in $\mathrm{KCl}$ fertilizers were applied at 80,70, and $35 \mathrm{~kg} \mathrm{ha}^{-1}$, respectively. Among the three fertilizers, $40 \%$ of the $\mathrm{N}$ and full doses of $\mathrm{P}$ and $\mathrm{K}$ were spread on the soil surface as a basal application before seeding. The remaining $60 \% \mathrm{~N}$ was applied as a side dressing at the tillering and panicle initiation stages.

The leaf area index (LAI) and above-ground dry mass (AGDM) were measured as growth variables in the principal stages of barley growth, i.e., initial-to-mid tillering, booting, heading, and early maturity. The LAI was measured using a plant canopy analyzer, LAI-2200C (LI-COR Inc., Lincoln, NE, USA), which can quantity the LAI of the canopy precisely and accurately, even in diffuse sunlight, using a light-diffusing cap and light scattering correction method. It measures the LAI using a fisheye lens based on gap fraction method [29]. The LAI measurement was made on day of year (DOY) 70, 72, 76, 81, 86, 90, 95, 106, 111, 116, and 125 in 2018 at CNU. At GNU, LAI was measured on DOY 98, 112, 126, 141, and 155 in 2018; DOY 68, 81, 102, 111, and 145 in 2019 for the autumn-seeded barley; DOY 102, 111, and 145 in 2019 for the spring-seeded barley. The LAI measurement was repeated three times in succession on the same plot. Meanwhile, plant samples were harvested to measure AGDM. Four samples of the whole above-ground plant were harvested in each plot on DOY 79, 95, 108, and 119 in 2018 at CNU. Plant sampling at GNU was done on DOY 97, 112, 126, 139, and 154 in 2018 and DOY 67, 80, 94, and 102 in 2019 for the autumn-sown barley and DOY 94, 116, and 123 in 2019 for the spring-sown barley. The plant samples were then separated into leaves, stem, and spike and oven-dried at $70{ }^{\circ} \mathrm{C}$ for one week depending on the sample condition. Plant sampling was performed to estimate biomass partitioning through photosynthesis using photosynthetically active radiation (PAR).

Weather data at the study sites were recorded using automated weather stations, WS-GP1 (Delta-T Devices, Cambridge, UK) at CNU and MetPRO (Campbell, Logan, UT, USA) at GNU. The daily average mean temperature, solar radiation, and precipitation were $9.90{ }^{\circ} \mathrm{C}, 14.37 \mathrm{MJ} \mathrm{m}^{-2} \mathrm{~d}^{-1}$, and $1.95 \mathrm{~mm} \mathrm{~d}^{-1}$, respectively, during the 2018 season (7 November 2017 to 20 June 2018) at CNU. These weather factors at GNU were $13.49^{\circ} \mathrm{C}, 14.78 \mathrm{MJ} \mathrm{m}^{-2} \mathrm{~d}^{-1}$, and $3.61 \mathrm{~mm} \mathrm{~d}^{-1}$ during the 2018 season (9 February 2018 to 25 June 2018) and $8.28{ }^{\circ} \mathrm{C}, 13.11 \mathrm{MJ} \mathrm{m}^{-2} \mathrm{~d}^{-1}$, and $1.95 \mathrm{~mm} \mathrm{~d}^{-1}$ during the 2019 season (30 October 2018 to 10 June 2019), respectively. 


\subsection{Proximal and Remote Sensing}

We obtained proximally sensed data on the ground at CNU, Gwangju in 2018 and both ground-based proximal sensing and UAS-based remote sensing data at GNU, Jinju in 2018 and 2019. A hand-held multispectral radiometer, MSR16R (CROPSCAN, Inc., Rochester, MN, USA), was used to measure the canopy reflectance of barley to determine growth conditions at the principal growth stages. The MSR16R can measure 16 wavebands in the range of 450-1750 nm. Further details on the system components, operation, and characteristics as well as the theory of operation can be found at the CROPSCAN website (http://www.cropscan.com/). The current study employed the three wavebands of 800,660 , and $560 \mathrm{~nm}$ with all the same band width of $10 \mathrm{~nm}$ to determine vegetation indices (VIs). Measurement was made on DOY 70, 72, 76, 81, 86, 90, 95, 106, 111, 116, and 125 in 2018 at CNU, Gwangju and DOY 98, 112, 126, 141, and 155 in 2018 and DOY 68, 81, 102, 111, and 145 in 2019 for the autumn-seeded barley and DOY 102, 111, and 145 in 2019 for the spring-seeded barley at GNU, Jinju. We designed to evaluate seasonal changes in canopy reflectance and LAI, generally measuring every week at CNU and every two weeks at GNU during the barley growing season. A UAS, eBee (senseFly, Cheseaux-sur-Lausanne, Switzerland) was used to obtain aerial images for the experimental barley field at GNU. The UAS comprised a fixed-wing UAV (a size of $960 \mathrm{~mm}$ and a weight of $700 \mathrm{~g}$ ) and a digital camera, Powershot S110 NIR (Cannon, Inc., Japan) with a 12.1 MP sensor and three wavebands of green $(G)$, red $(R)$, and near infra-red (NIR). The center wavelengths of the bands were $550(\mathrm{G}), 625(\mathrm{R})$, and $850 \mathrm{~nm}$ (NIR). UAS-based aerial images were taken on DOY $87,101,115,130,144$, and 158 in 2018 and DOY 53, 67, 81, 95, 102, 123, and 144 in 2019. These image data were processed radiometrically and mosaicked to form complete scenes of the experimental field using Pix4D mapper software (Pix4D S.A., Prilly, Switzerland). The processed images were then geometrically corrected using ERDAS IMAGINE software (Hexagon Geospatial, Madison, AL, USA), followed by georeferencing and registration using ArcGIS software (Esri, Inc., Redlands, CA, USA).

The VIs of interest for assessing the barley canopy growth based on the integrated modeling system were the normalized difference vegetation index (NDVI) [30], optimized soil adjusted vegetation index (OSAVI) [31], modified triangular vegetation index 1 (MTVI1) [32], and re-normalized difference vegetation index (RDVI) [33]. The four VIs were determined using the following formulas:

$$
\begin{gathered}
\text { NDVI }=\left(\mathrm{R}_{800}-\mathrm{R}_{660}\right) /\left(\mathrm{R}_{800}+\mathrm{R}_{660}\right) \\
\text { RDVI }=\left(\mathrm{R}_{800}+\mathrm{R}_{660}\right) / \sqrt{\mathrm{R}_{800}+\mathrm{R}_{660}} \\
\text { OSAVI }=\left(\mathrm{R}_{800}-\mathrm{R}_{660}\right) /\left(\mathrm{R}_{800}+\mathrm{R}_{560}+0.16\right) \\
\text { MTVI1 }=1.2 \cdot\left[1.2 \cdot\left(\mathrm{R}_{800}-\mathrm{R}_{660}\right)-2.5 \cdot\left(\mathrm{R}_{660}-\mathrm{R}_{560}\right)\right]
\end{gathered}
$$

where $R_{800}, R_{660}$, and $R_{560}$ represent reflectance at 800,660 , and $560 \mathrm{~nm}$, respectively.

\subsection{RSCM System for Barley}

The RSCM is a process-based crop-modeling system, which can simulate crop growth and yield using simple inputs owing to the integration of RS information (Figure 1). The RSCM for barley simulated daily barley growth in four simple processes, i.e., determining daily growing degree days (GDD), absorption of incident solar radiation by the crop canopy, daily increase in above-ground dry mass, and daily change in LAI (increase or senescence), based on mathematical equations (Table 1). The RSCM fitted a simulated LAI curve to the observed LAI curve using a Bayesian procedure as a part of the within-season calibration method. The LAI is a three-dimensional concept, while the reflectance by plants of solar radiation is two-dimensional since the plant canopies are the top surface of the plants. We assumed that a log-log regression model with a slope of $\approx 2 / 3$ could define the relationship between 
reflectance and LAI [34]. Based on this, we formulated the correlations between the LAI and the four VIs (MTVI1, NDVI, RDVI, and OSAVI) using log-log linear regression models as follows.

$$
\log \left(V I_{t}\right)=\alpha_{V I}+\beta_{V I} \log \left(L A I_{t}\right)+\varepsilon_{t}
$$

where $\alpha_{V I}, \beta_{V I}$, and $\epsilon_{t}\left(\sim N\left(0, \sigma_{V I}^{2}\right)\right.$ represent intercept, slope, and error of the linear regression model, respectively. The progression of LAI for each pixel was described by the RSCM-barley system, using four parameters $\theta=\left(L_{0}, a, b\right.$, and $\left.c\right)$. These parameters were designed to be generated from the prior distribution $\psi \sim N(\mu, D)$, ranging between 0 and 1 using the following transformations.

$$
\begin{gathered}
\psi=\left(\psi_{1}, \psi_{2}, \psi_{3}, \psi_{4}\right)=\left(\log \frac{a}{1-a}, \log \frac{b}{1-b}, \log \frac{c}{1-c}, \log \frac{L_{0}}{1-L_{0}}\right) \\
\theta=\theta(\psi)=\left(\frac{e^{\psi_{1}}}{1+e^{\psi_{1}}}, \frac{e^{\psi_{2}}}{1+e^{\psi_{2}}}, \frac{e^{\psi_{3}}}{1+e^{\psi_{3}}}, \frac{e^{\psi_{4}}}{1+e^{\psi_{4}}},\right)
\end{gathered}
$$

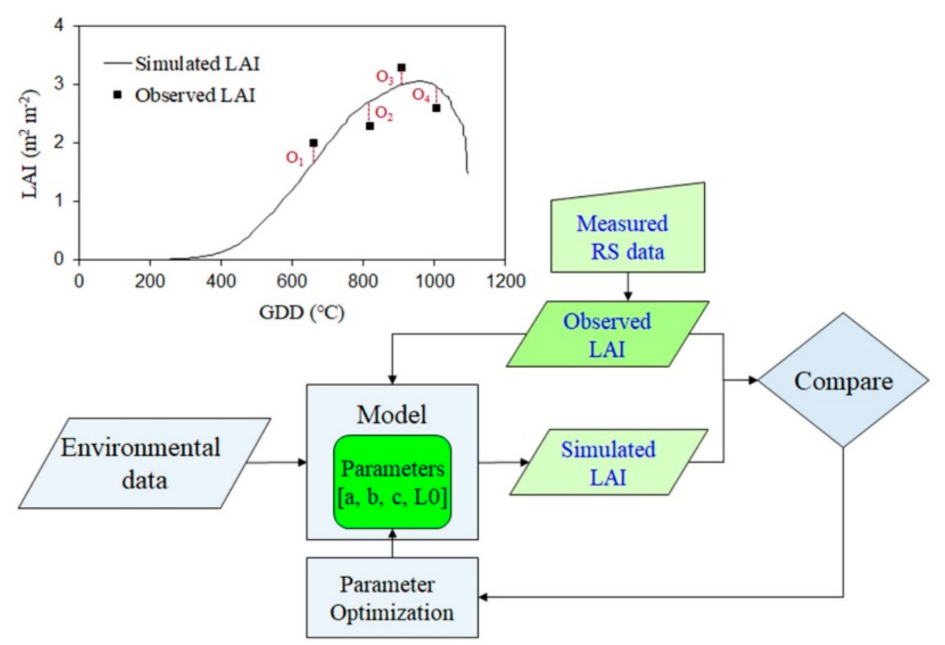

Figure 1. Diagrammatic representation of the remote sensing-integrated crop model (RSCM) for barley; model parameterization is based on remote sensing (RS) information and simulated versus observed

\begin{tabular}{|c|c|}
\hline Equations & Description \\
\hline$\Delta \mathrm{D}=\operatorname{MAX}\left[\mathrm{T}-\mathrm{T}_{\mathrm{b}}, 0\right]$ & $\begin{array}{l}\Delta \mathrm{D} \text {, daily change in growing degree days (GDD); } \mathrm{T} \text {, daily mean } \\
\text { temperature; } \mathrm{T}_{\mathrm{b}} \text {, crop specific base temperature }\end{array}$ \\
\hline$Q=\beta \cdot R \cdot\left(1-e^{-k \cdot L A I}\right)$ & $\begin{array}{c}\text { Q, absorption of incident solar radiation }(\mathrm{R}) ; \beta \text {, fraction of } \mathrm{R} ; \mathrm{k} \text {, crop-specific } \\
\text { light extinction coefficient; LAI, leaf area index }\end{array}$ \\
\hline$\Delta \mathrm{M}=E \cdot \mathrm{Q}$ & $\Delta \mathrm{M}$, daily increase in above-ground dry mass; $E$, radiation use efficiency \\
\hline$\Delta \mathrm{L}=\Delta \mathrm{M} \cdot \mathrm{P}_{1} \cdot \mathrm{S}$ & $\begin{array}{c}\Delta \mathrm{L} \text {, daily LAI increase; } \mathrm{P} 1 \text {, fraction of } \Delta \mathrm{M} \text { allocated to new leaves; } \mathrm{S} \text {, specific } \\
\text { leaf area }\end{array}$ \\
\hline$P_{1}=\operatorname{Max}\left[1-a \cdot e^{b \cdot D}, 0\right]$ & $\begin{array}{c}\mathrm{P}_{1} \text {, dimensionless leaf-allocation function; } \mathrm{a} \text { and } \mathrm{b} \text {, parameters that control } \\
\text { magnitude and shape of the function; } \mathrm{D} \text {, cumulative GDD }\end{array}$ \\
\hline$\Delta \mathrm{G}=\mathrm{P}_{2} \cdot \Delta \mathrm{M}$ & $\Delta \mathrm{G}$, daily increase in grain; $\mathrm{P}_{2}$, fraction of $\Delta \mathrm{M}$ partitioned to grains \\
\hline $\mathrm{P}_{2}=\operatorname{Max}\left[1-\mathrm{P}_{\mathrm{a}} \cdot \mathrm{e}_{\mathrm{b}}^{\mathrm{P}_{\mathrm{b}}} \cdot f \mathrm{G}_{\mathrm{d}, 0}\right]$ & $\begin{array}{l}P_{2,} \text { dimensionless grain-partitioning parameter; } P_{a} \text { and } P_{b} \text {, parameters that } \\
\text { control the magnitude and shape of the function; and } f G_{d} \text { is the grain } \\
\text { partitioning factor based on the cumulative GDD }\end{array}$ \\
\hline
\end{tabular}
leaf area index (LAI) according to the optimization process (top sub-panel).

Table 1. Equations applied in the remote sensing-integrated crop model (RSCM) for barley.

We obtained both the regression coefficients $\left(\alpha_{\ell}, \beta_{\ell}, \sigma_{\ell}^{2}\right), \ell=1,2,3$, and 4 for each VI and the hyper-parameters $(\mu, D)$ from the data collected in this study for parameterization. These included both the VIs and the measured LAI values. The parameter $\mu$ was specified using the 'before-calibration' values $\left(L_{0}=0.2, a=3.25 \times 10^{-1}, b=1.25 \times 10^{-3}\right.$, and $\left.c=1.25 \times 10^{-3}\right)$ as feasible minimum values before 
the calibration procedure. Parameter $\mathrm{D}$ is a diagonal matrix with all diagonal elements equivalent to 0.5. The following numerical procedure was implemented to achieve $\theta$ for each pixel:

Step 1: $\mu$ was set as the initial estimate of $\psi$ for each pixel. as follows.

Step 2: $L A I_{t}=\widetilde{G}(t ; \psi)=G(t ; \theta(\psi))$ was defined and the objective function considered

$$
\sum_{\ell=1}^{5}\left\{\frac{1}{\sigma_{\ell}^{2}} \sum_{t=1}^{n}\left(\log V I_{\ell t}-\alpha_{\ell}-\beta_{\ell} \log \widetilde{G}(t ; \psi)\right)^{2}\right\}+(\psi-\mu)^{\prime} D^{-1}(\psi-\mu)
$$

Step 3: The simulated curve was generated for each pixel from the estimated $\psi$ in Step 2.

Step 4: The $\mu, D$ was updated as the sample means and sample variances of the estimates in Step 2. In this procedure, the parameter $\psi$ was estimated by minimizing the above function, and the optimization was performed using the POWELL optimization routine [35] for one-point simulation cases and the Quasi-Newton minimizer [36] for two-dimensional simulation cases.

\subsection{Statistical Analysis}

The performance of the RSCM system was evaluated using a two sample-paired $t$-test, and two statistical indices of root mean squared error (RMSE) and the Nash-Sutcliffe model efficiency (NSE) [37] in R software (https://www.r-project.org/). The NSE determines the relative magnitude of the residual variance of simulated data compared to the observed data variance, evaluating how well the plot of observed versus simulated data fits the 1:1 line. NSE values can range between $-\infty$ and 1, meaning that the model is dependable if the value is closer to 1 . Simulated values are smaller or larger than the observed data when NSE values are close to zero.

\section{Results}

\subsection{Parameterization and Calibration of RSCM}

We estimated the specific barley growth parameters of radiation use efficiency (RUE), specific leaf area (SLA), and light extinction coefficient (k) from the data set obtained at CNU in 2018 for effective calibration of the model. The RUE $(\varepsilon)$ was determined from the slope of the linear regression model between the amounts of accumulated PAR absorbed by barley canopies and AGDM for four barley cultivars (Figure 2a). The estimated value of RUE was $3.1 \mathrm{~g} \mathrm{MJ}^{-1}$. The SLA was also determined using the linear relationship between LAI and leaf dry weight for five barley cultivars (Figure 2b). We included an additional cultivar in this specific case for the improved regression analysis. The slope from the linear regression model expressed the value $\left(0.012 \mathrm{~m}^{2} \mathrm{~g}^{-1}\right)$ of SLA. The value of $\mathrm{k}$ was estimated based on the relationship between LAI and canopy light interception $\left(Q_{0}=1-e^{-k^{*} L A I}\right)$ for four barley cultivars (Figure 3 ). We determined $\mathrm{k}$ values presuming that barley canopies could intercept $\approx 90 \%$ of light at the maximum LAI. The estimated $\mathrm{k}$ values for the barley cultivars using the light interception equation $\left(\mathrm{Q}_{0}\right)$ varied from -0.58 to -0.65 (unitless). The parameter $\mathrm{k}$ was considered to have a mean value of -0.62 . 

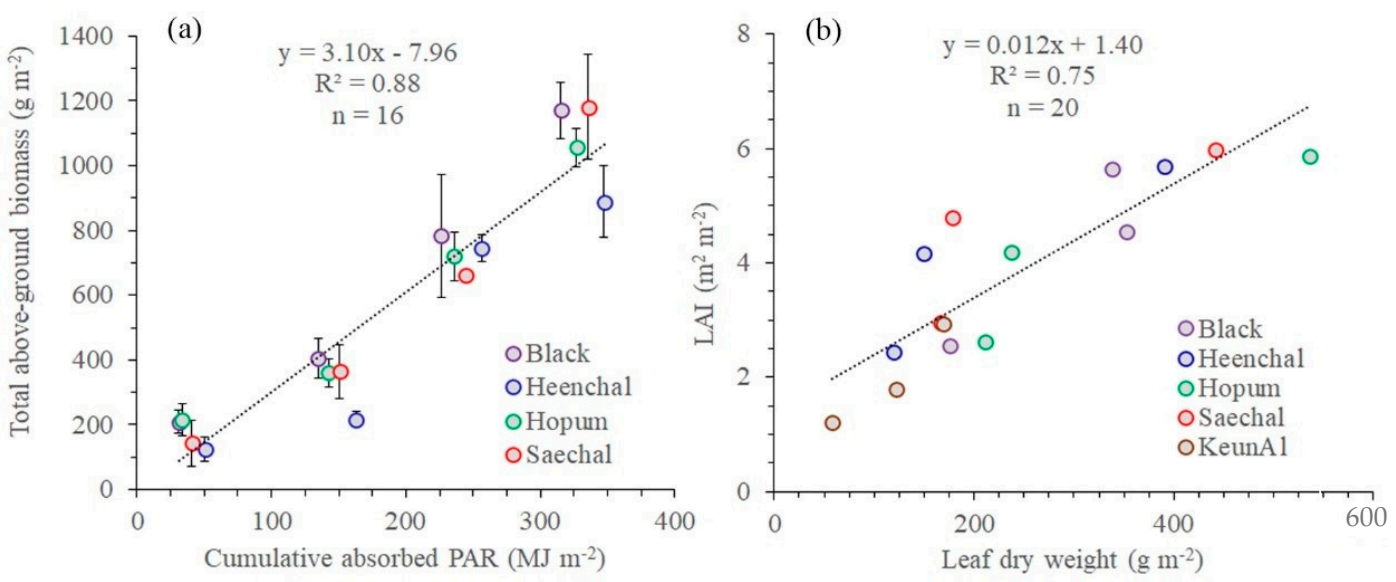

Figure 2. Determination of (a) a radiation use efficiency (RUE, $\varepsilon=3.1 \mathrm{~g} \mathrm{MJ}^{-1}$ ) and (b) a specific leaf area (SLA $=0.012 \mathrm{~m}^{2} \mathrm{~g}^{-1}$ ) for four (five in the case of SLA) barley cultivars. PAR and LAI represent photosynthetically active radiation and leaf area index.
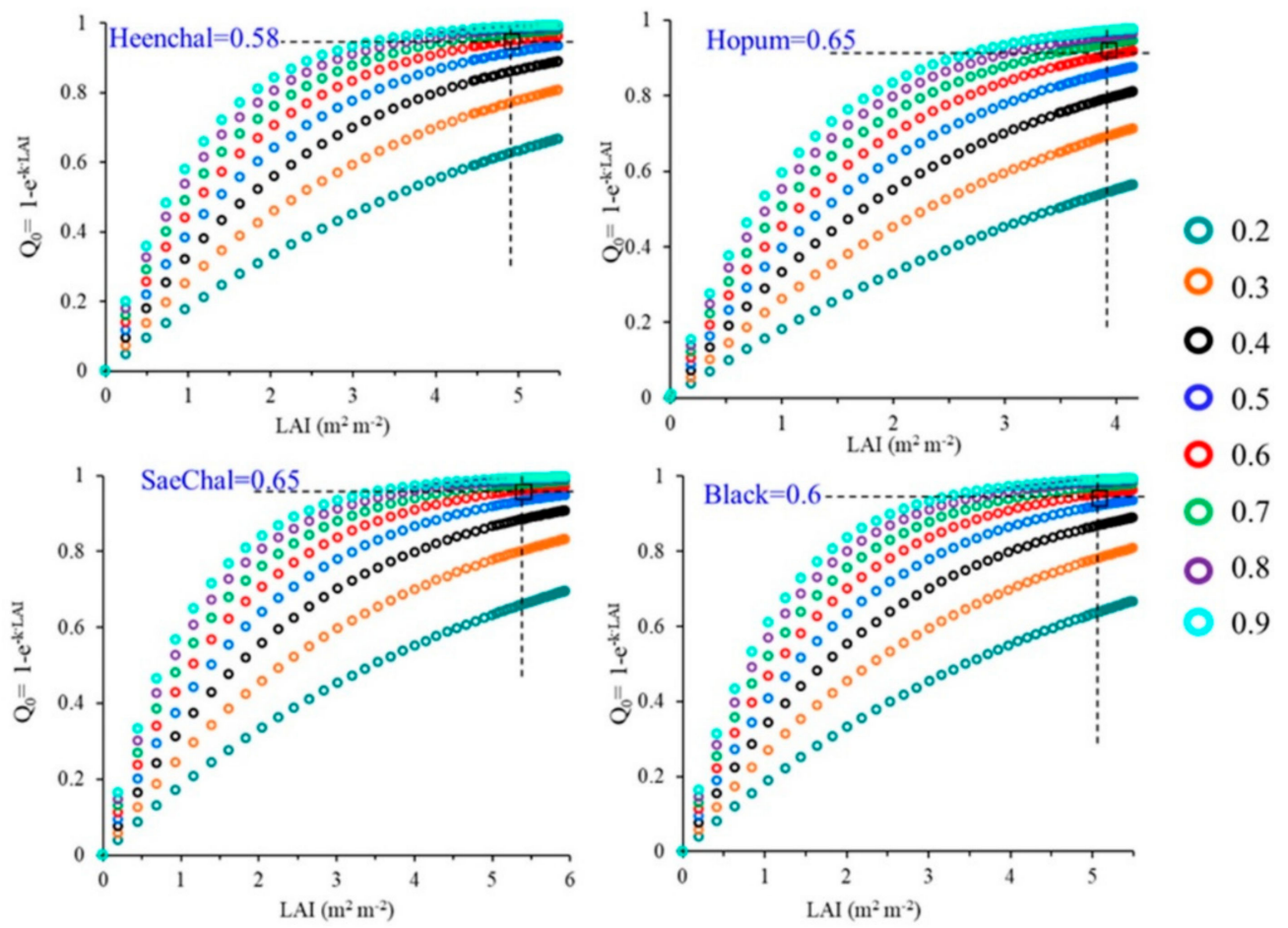

Figure 3. Determination of a light extinction coefficient $(\mathrm{k}=0.62)$ based on the relationship between leaf area index (LAI) and canopy light interception $\left(\mathrm{Q}_{0}=1-\mathrm{e}^{-\mathrm{k}^{*} \mathrm{LAI}}\right)$ for four barley cultivars.

The RSCM system was calibrated using the dataset employed in the model parameterization, based on the estimated parameters. The RSCM simulated LAI, AGDM, and yield were in statistically significant agreement with the corresponding measured values for the four barley cultivars (Figures 4 and 5 , and Table 2), which were verified using a within-season calibration procedure (refer to Table A1). The RMSE and NSE values for LAI ranged from 0.18 to $0.35 \mathrm{~m}^{2} \mathrm{~m}^{-2}$ and from 0.78 to 0.91 , while those for AGDM ranged from 53.4 to $91.4 \mathrm{~g} \mathrm{~m}^{-2}$ and from 0.78 to 0.88 , respectively (Table 2). Simulated grain yields agreed with the measured grain yields without a significant difference $(p=0.12)$ according to a two-sample $t$-test $(\alpha=0.05)$ and with RMSE of 0.624 ton $^{-1} a^{-1}$ (Figure 5). It is assumed that the small arithmetic overestimation in the simulated yields of Heenchal, Hopum, and Saechal are attributable to somewhat small overestimations in the matching LAI values. 

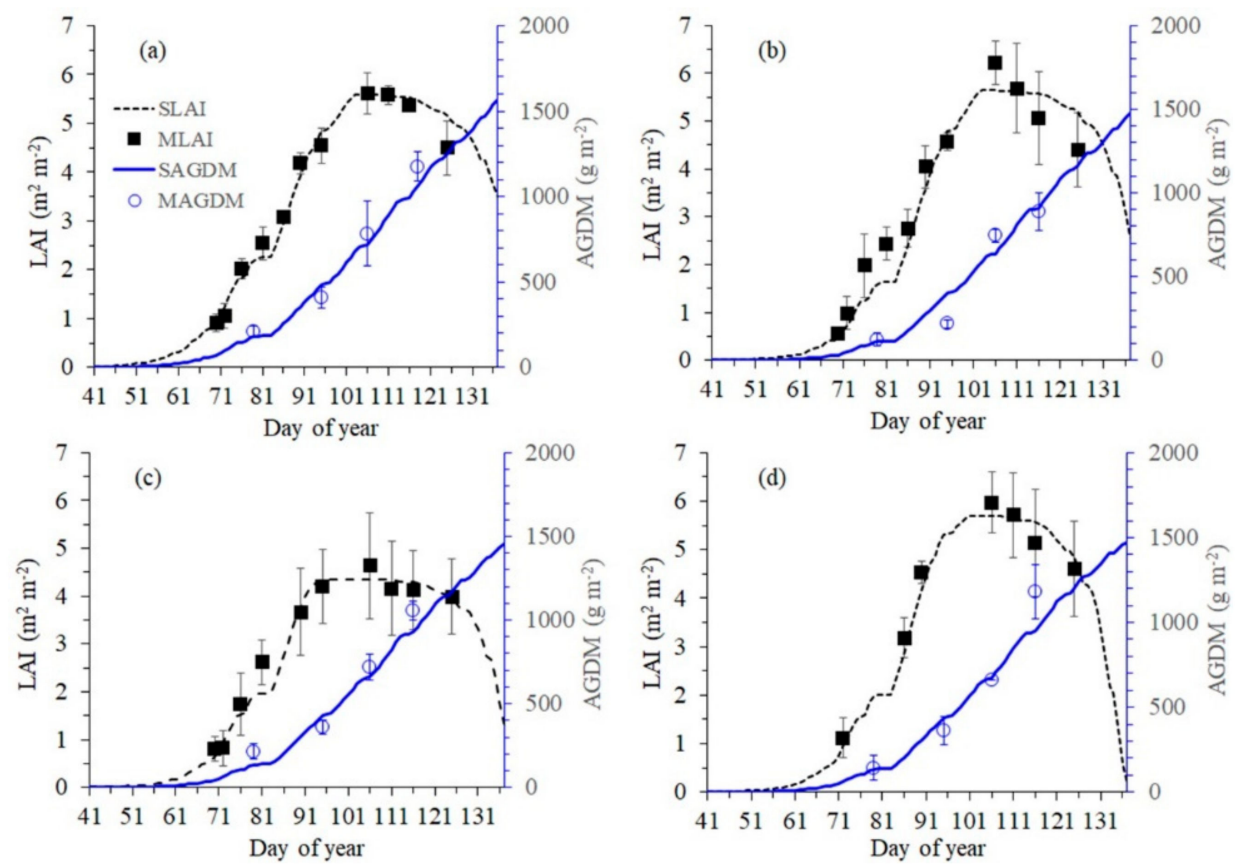

Figure 4. Simulated (S) versus measured (M) leaf area index (LAI) and above-ground dry mass (AGDM) for four barley cultivars (a) Black, (b) Heenchal, (c) Hopum, and (d) Saechal at Chonnam National University, Gwangju, South Korea in 2018 for model calibration. Vertical bars represent standard deviation of each mean value $(n=3)$ at $95 \%$ confidence intervals.

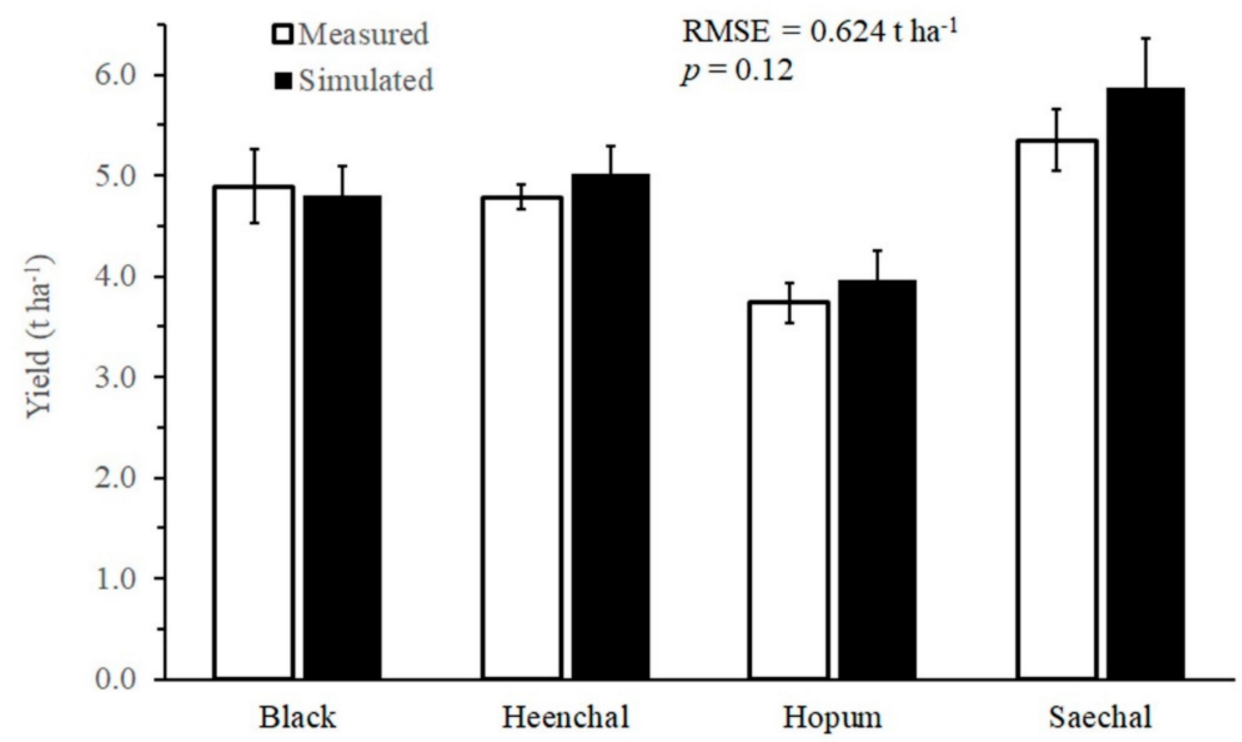

Figure 5. Comparison between simulated and measured grain yields of four barley cultivars at Chonnam National University, Gwangju, South Korea in 2018 for model calibration. RMSE, NSE, and $p$ stands for root mean square error, Nash-Sutcliffe efficiency, and $p(\alpha=0.05)$ at a two-sample $t$-test. Vertical bars represent SE of each mean value $(n=3)$. 
Table 2. Error statistics of root mean square (RMSE) and Nash-Sutcliffe efficiency (NSE) between the simulated (S) and measured (M) values of leaf area index (LAI), and above-ground dry mass (AGDM) of four barley cultivars at Chonnam National University (CNU), Gwangju, South Korea in 2018 for model calibration.

\begin{tabular}{|c|c|c|c|c|c|c|c|c|}
\hline \multirow{3}{*}{ Cultivar } & \multicolumn{4}{|c|}{ LAI } & \multicolumn{4}{|c|}{ AGDM } \\
\hline & $S$ & M & RMSE & NSE & S & $\mathbf{M}$ & RMSE & NSE \\
\hline & \multicolumn{3}{|c|}{$\longrightarrow \mathrm{m}^{2} \mathrm{~m}^{-2} \longrightarrow$} & $n / \mathbf{a}$ & \multicolumn{3}{|c|}{$-\mathrm{g} \mathrm{m}^{-2}-$} & $n / \mathbf{a}$ \\
\hline Black & 4.18 & 4.11 & 0.18 & 0.91 & 643.3 & 611.1 & 78.5 & 0.78 \\
\hline Heenchal & 3.52 & 3.43 & 0.35 & 0.83 & 548.0 & 515.1 & 53.4 & 0.88 \\
\hline Hopum & 3.12 & 3.07 & 0.34 & 0.78 & 540.3 & 588.0 & 60.8 & 0.81 \\
\hline Saechal & 4.38 & 4.32 & 0.26 & 0.80 & 561.8 & 588.0 & 91.4 & 0.81 \\
\hline
\end{tabular}

The number of data $(n)$ with three replications $=11$ for LAI in both Black and Heenchal, $n=10$ for LAI in Hopum, $n=7$ for LAI in Saechal, and $n=4$ for AGDM for all the four cultivars.

\subsection{Validation of RSCM and Two-Dimensional Simulation of Barley}

The barley-modeling system was validated for its accuracy using a dataset separately obtained at GNU in the 2018 and 2019 barley seasons. The modeling system simulated LAI, AGDM, and yield in agreement with the corresponding measured values with statistically acceptable accuracies in both seasons (Figures 6 and 7, and Table 3) based on the model re-parameterization process (refer to Table A1). Simulated LAI and AGDM values agreed with the measured values with an RMSE of 0.17 $\mathrm{m}^{2} \mathrm{~m}^{-2}$ and an NSE of 0.82 for LAI and with an RMSE of $74.89 \mathrm{~g} \mathrm{~m}^{-2}$ and an NSE of 0.55 for AGDM in the 2018 season. There was no significant difference $(p=0.96)$ between simulated and measured yields according to a two-sample $t$-test $(\alpha=0.05)$, with an RMSE of 0.701 ton ha ${ }^{-1}$. During the 2019 barley season, the modeling system simulated LAI and AGDM with an NSE of 0.93 for LAI and 0.21 for AGDM for the autumn barley and with an NSE of 0.70 for LAI and 0.79 for AGDM for the spring barley (Table 3$)$. The simulated yield was not significantly different $(p=0.76$ for the autumn barley and 0.37 for the spring barley) from the measured yield according to two-sample $t$-tests $(\alpha=0.05)$, with RMSEs of 1.177 ton ha ${ }^{-1}$ in the autumn season and 1.178 ton ha ${ }^{-1}$ in the spring season.
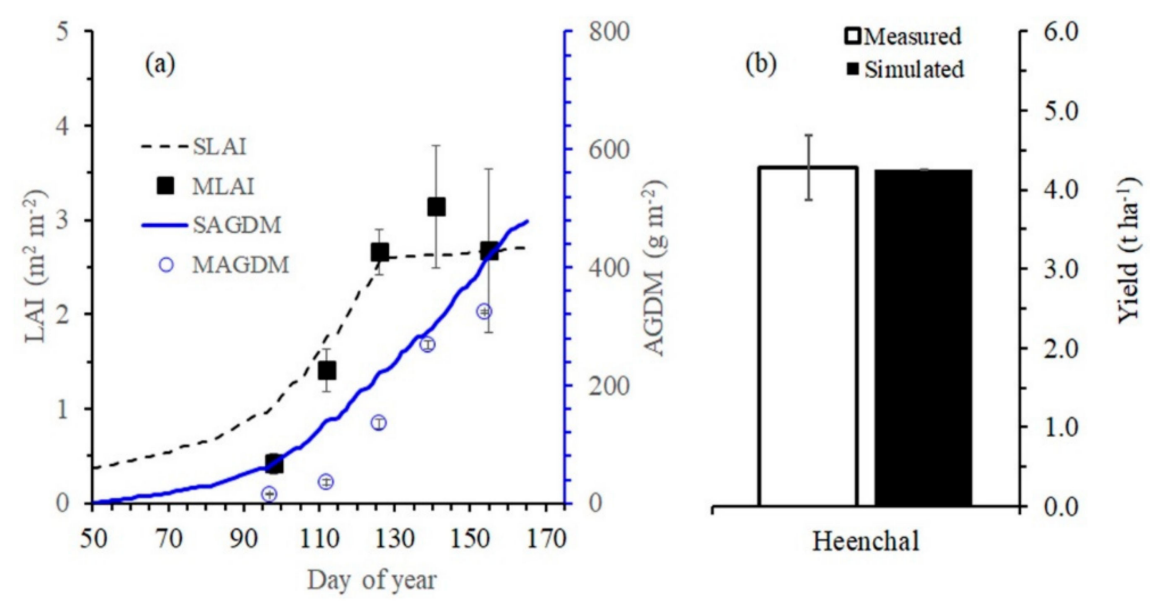

Figure 6. Simulated (S) versus measured (M) leaf area index (LAI) and above-ground dry mass (AGDM) (a) and comparison between simulated and measured grain yield (b) at Gyeongsang National University, Jinju, South Korea in 2018 for model validation. Vertical bars represent standard deviation of each mean value $(n=3)$ at $95 \%$ confidence intervals in $(\mathbf{a})$ and SE of each mean value $(n=3)$ in $(\mathbf{b})$. 

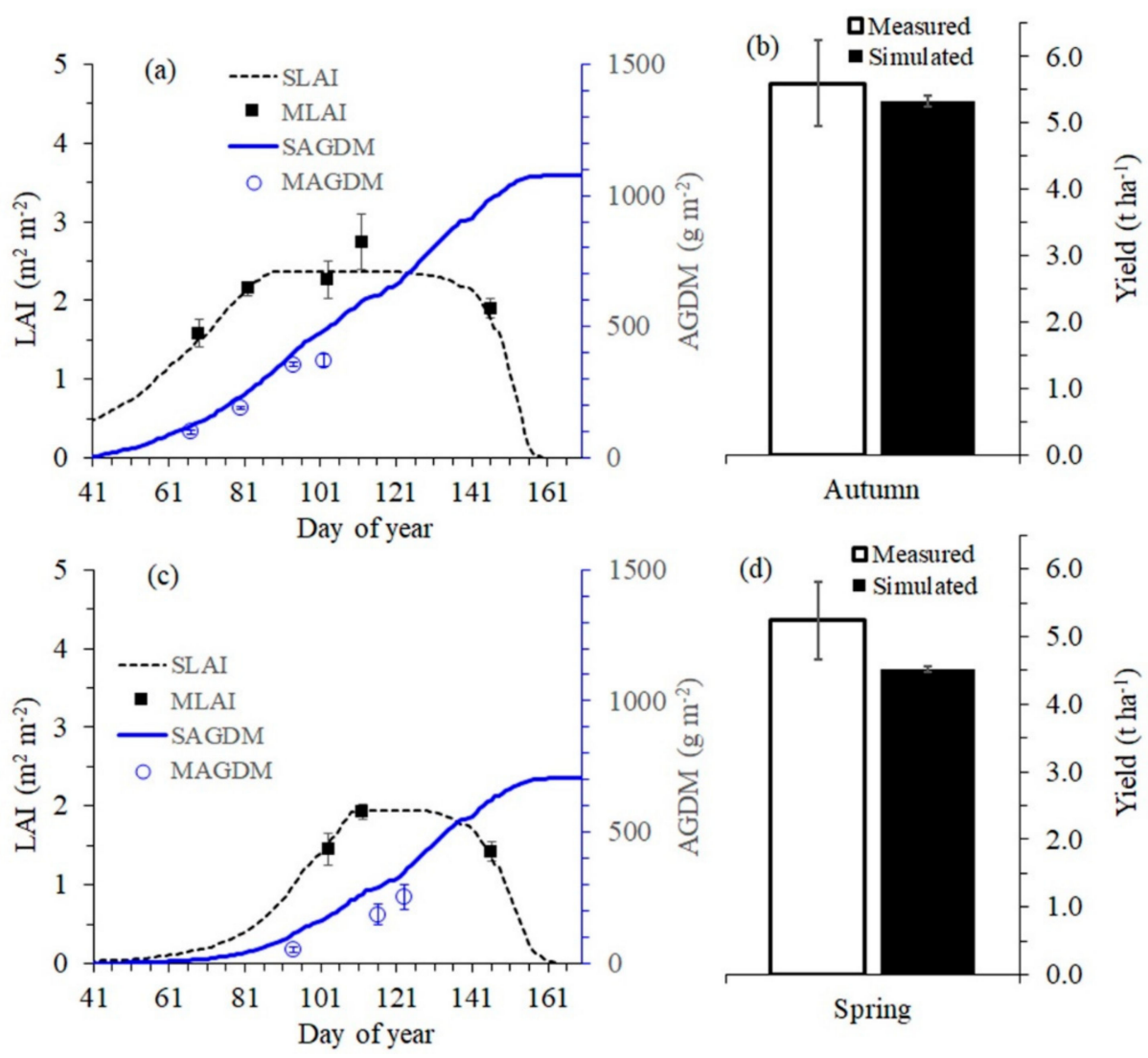

Figure 7. Simulated (S) versus measured (M) leaf area index (LAI) and above ground dry mass (AGDM) $(\mathbf{a}, \mathbf{c})$ and comparison between simulated and measured grain yields $(\mathbf{b}, \mathbf{d})$ of autumn-sown $(\mathbf{a}, \mathbf{b})$ and spring-sown (c,d) barely for model validation at Gyeongsang National University, Jinju, South Korea in 2019. Vertical bars represent standard deviation of each mean value $(n=3)$ at $95 \%$ confidence intervals in subplots $(\mathbf{a}, \mathbf{b})$ and SE of each mean value $(n=3)$ in subplots $(\mathbf{b}, \mathbf{d})$.

Table 3. Error statistics of root mean square (RMSE) and Nash-Sutcliffe efficiency (NSE) between the simulated (S) and measured (M) values of leaf area index (LAI) of Heenchal seeded in spring and autumn at Gyeongsang National University (GNU), Jinju, South Korea in 2018 and 2019 for model validation.

\begin{tabular}{|c|c|c|c|c|c|c|c|c|}
\hline \multirow{3}{*}{ Seeded Season } & \multicolumn{4}{|c|}{ LAI } & \multicolumn{4}{|c|}{ AGDM } \\
\hline & S & $\mathbf{M}$ & RMSE & NSE & $S$ & $\mathbf{M}$ & RMSE & NSE \\
\hline & \multicolumn{3}{|c|}{$-\mathrm{m}^{2} \mathrm{~m}^{-2}-$} & $n / \mathbf{a}$ & \multicolumn{3}{|c|}{$-\mathrm{g} \mathrm{m}^{-2} \longrightarrow$} & $n / \mathbf{a}$ \\
\hline Autumn 2018 & 2.08 & 2.06 & 0.16 & 0.96 & 225.8 & 156.0 & 74.89 & 0.55 \\
\hline Spring 2019 & 1.60 & 1.60 & 0.07 & 0.93 & 250.9 & 164.4 & 88.41 & 0.21 \\
\hline Autumn 2019 & 2.03 & 2.13 & 0.19 & 0.70 & 310.2 & 254.7 & 64.96 & 0.79 \\
\hline
\end{tabular}

The number of data $(n)$ with three replications $=5$ for both LAI and AGDM in 2018, $n=5$ for LAI and 4 for AGDM in autumn 2019, and $n=3$ for both LAI and AGDM in spring 2019.

The RSCM for barley was also used to simulate the two-dimensional variation in barley growth and yield for both the 2018 and 2019 season barley datasets (Figures 8 and 9). The simulated normalized yield index (NYI) in the 2018 autumn barley season showed a mean of 0.675 with a standard deviation of \pm 0.239 at the $95 \%$ confidence interval (SD) while the mean and SD values of LAI and AGDM at 60 days after rejuvenation (the restoration of growth) were $0.45 \pm 0.42 \mathrm{~m}^{2} \mathrm{~m}^{-2}$ and $29.87 \pm 31.00 \mathrm{~kg} \mathrm{ha}^{-1}$. Likewise, the modeling system simulated barley NYI in the 2019 autumn season with a mean of 0.532 $\pm 0.149 \mathrm{SD}$ while those of LAI and AGDM at 60 days after rejuvenation showed means of $3.19 \pm 0.356$ $\mathrm{m}^{2} \mathrm{~m}^{-2}$ and $730.6 \pm 44.1 \mathrm{~kg} \mathrm{ha}^{-1}$, respectively. During the 2019 spring season, NYI showed a mean of 
$0.535 \pm 0.111$ SD while the mean and SD values of LAI and AGDM at 60 days after rejuvenation were $1.75 \pm 0.403 \mathrm{~m}^{2} \mathrm{~m}^{-2}$ and $385.6 \pm 60.641 \mathrm{~kg} \mathrm{ha}^{-1}$, respectively.
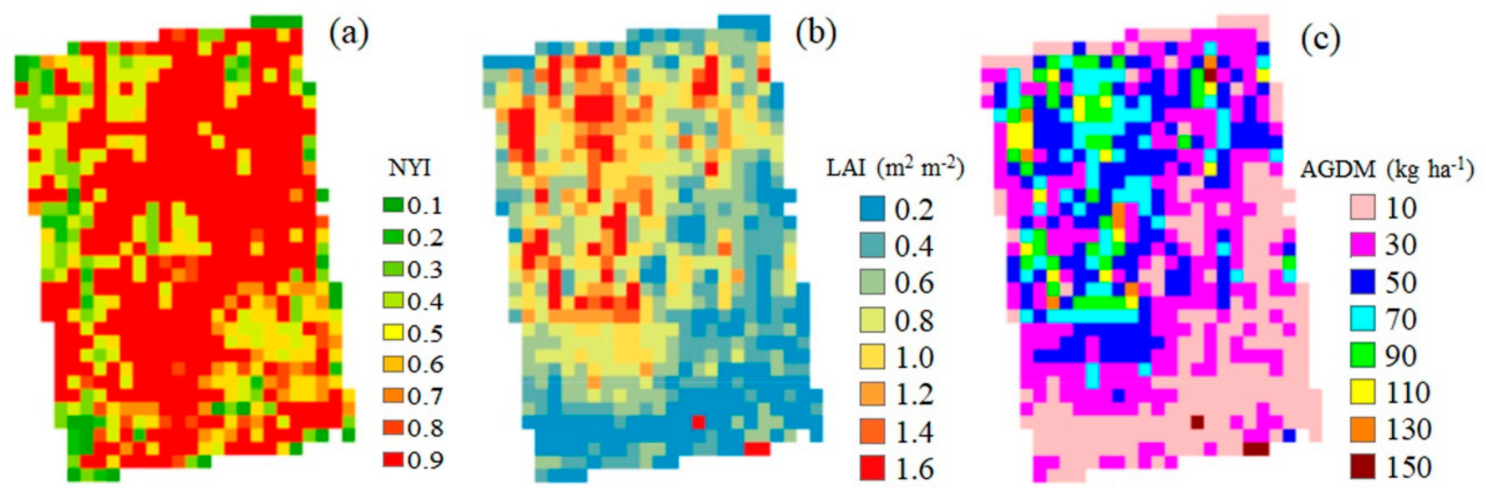

Figure 8. Two-dimensional field variations in the simulated barley variables of normalized yield index, NYI (a), leaf area index, LAI (b), and above ground dry mass, AGDM (c) at 60 days after rejuvenation at Gyeongsang National University, Jinju, South Korea in 2018.

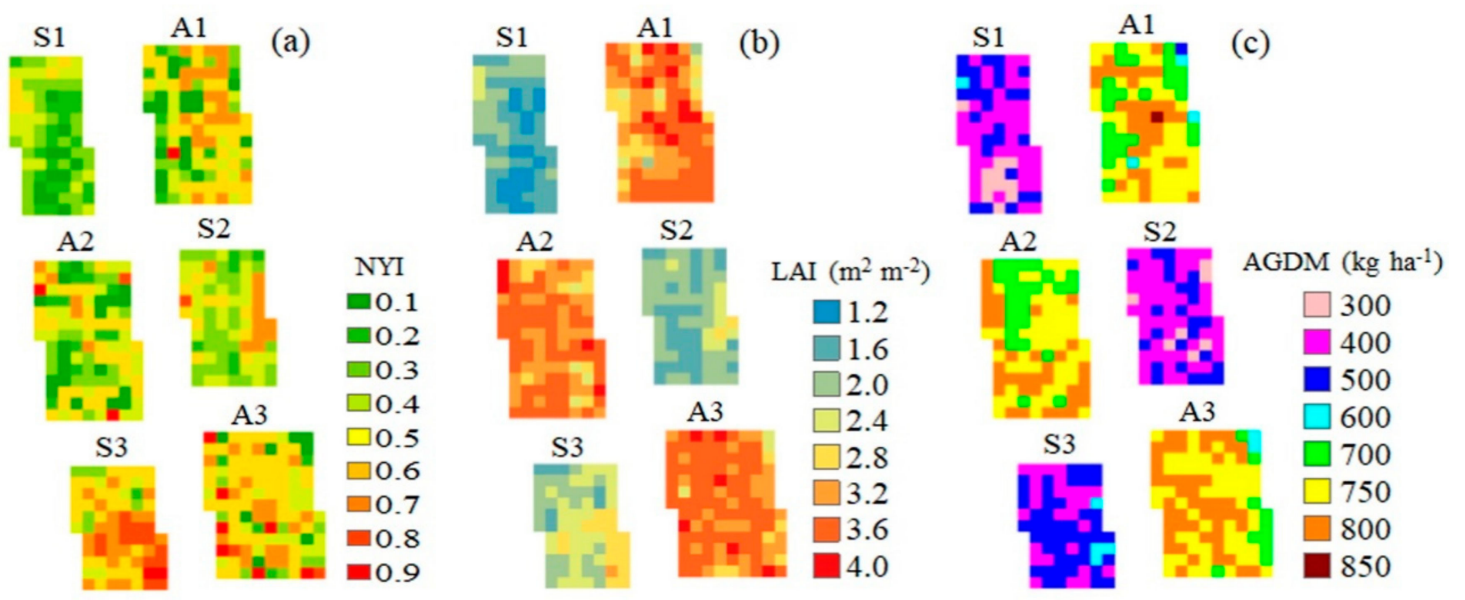

Figure 9. Two-dimensional field variations in the simulated barley variables of normalized yield index, NYI (a), leaf area index, LAI (b), and above ground dry mass, AGDM (c) at 60 days after rejuvenation in autumn (A) and spring (S) at Gyeongsang National University, Jinju, South Korea in 2019.

\section{Discussion}

Parameterization in crop simulation modeling is used to reduce the complexity of the model and explore the best fit for the experiment $[7,20]$. In this study, specific barley growth parameters (RUE, SLA, and k) were estimated from the CNU data set at Gwangju for the successful calibration of the model. The RUE can be determined from the slope of the linear regression of the gross amount of AGDM that is produced by absorbing PAR [38]. Earlier studies report that different cultivation management and stress conditions can affect the RUE value of barley [39-41]. The estimated RUE value in this study was somewhat higher than those reported earlier. A crop model simulates the crop responses based on ideal growth and management practices. In the current study, we estimated the barley RUE value from the optimum cultivation field. According to Charles-Edward et al. [42], the amount of PAR intercepted in crop canopy can depend on leaf canopy distribution. Additionally, leaf angle distribution can significantly affect light interception [43]. The $\mathrm{k}$ value (-0.62) estimated in the current study was a bit larger than the $k$ value $(-0.69)$ from the earlier reports [44,45]. The SLA, which is defined as the total leaf area divided by the total leaf weight, was adopted as a concept in the analysis of whole plant growth [46]. The SLA, which is sensitive to leaf thickness and leaf area, is likely to affect net photosynthesis, leaf structure, crop growth rate, and yield [47]. 
A well-calibrated crop model can reproduce field conditions of crop productivities with a dependable accuracy [7]. Our calibration study demonstrated this feature in crop modeling. The RSCM system is designed to simulate crop growth with simple inputs owing to the integration of remote sensing information. There were earlier efforts to develop the integrated crop-modeling system for rice and soybean $[2,6,23]$. The current study showed that the RSCM system, utilizing the within-season calibration procedure, could reproduce barley growth (i.e., LAI and AGDM) and grain yield with statistically acceptable accuracy. Although there were some abnormalities for the simulated AGDM in validation for both the 2018 and 2019 barley seasons, the simulated LAI and yield showed statistically significant agreement with the corresponding measured values in the RSCM for barley. There have been a few of earlier study results comparable to the current report, in terms of evaluating and monitoring barley growth conditions based on RAS images [48-50]. One of these studies applied an empirical modeling approach to estimate barley biomass [48]. The other studies investigated experimental methodologies for yield and fertilization analysis [49] and monitoring growth of biennial cereal crops including barley [50]. We assume that a process-based mathematical crop model has an advantage of understating crop growth and development processes in comparison with an empirical crop modeling technique [16]. A substantial benefit of the current mathematical modeling system is that it can simulate the development of major agronomic crops based on the integration of RS information from various platforms, i.e., either earth observing optical satellites [24,25] or RAS [16].

The current study also showed the practical possibility of monitoring barley growth and yield using a RAS. Nevertheless, the modeling system requires better quantitative RS images for more advanced applications. The desired improvements include radiometrically well-calibrated image data accompanied by a reasonably detailed sensor. It is clear that improved RAS images will be more useful for monitoring crop conditions and productivity [16]. It would also add value to test the extendibility of the system.

\section{Conclusions}

In this study, we estimated barley growth parameters (i.e., $3.10 \mathrm{~g} \mathrm{MJ}^{-1}$ for RUE, 0.65 for $\mathrm{k}$, and $0.012 \mathrm{~m}^{2} \mathrm{~g}^{-1}$ for SLA) to use in an RSCM for barley and demonstrated the capability of the modeling system of reproducing barley growth and yield. We assumed that the modeling system was well adaptable for barley growth monitoring and field management projects owing to the integration with RS information from various platforms (e.g., satellite aboard sensors and human or remotely controlled UAS). The barley RSCM system should use well-quantified RS images for more precise monitoring of barley productivity and other cultivation management options.

Author Contributions: Conceptualization, J.K., K.D.L., and S.I.S.; methodology, A.R.S. and S.J.; software, J.K.; validation, A.R.S., J.K., and S.J.; formal analysis, J.K., K.D.L., and S.I.S.; investigation, A.R.S., T.S., S.J., S.I.S., and K.D.L.; resources, J.K., S.I.S., and K.D.L.; data curation, A.R.S., K.D.L., S.J., S.I.S., and T.S.; writing-original draft preparation, A.R.S. and J.K.; writing-review and editing, J.K.; visualization, A.R.S. and S.J.; supervision, J.K. and S.I.S.; project administration, K.D.L. and S.J.; funding acquisition, J.K. All authors have read and agreed to the published version of the manuscript.

Funding: This work was performed with the support of Cooperative Research Program for Agriculture Science and Technology Development (Project No. PJ013841022018) from the Rural Development Administration, Republic of Korea. Partial support was taken from the Basic Science Research Program through the National Research Foundation of Korea (NRF), funded by the Ministry of Education, Science, and Technology (NRF-2018R1D1A1B07042925).

Conflicts of Interest: The authors declare no conflict of interest. 


\section{Appendix A}

Table A1. Converged parameters of initial leaf area index $\left(\mathrm{L}_{0}\right)$ and leaf partitioning and senescence (a, $\mathrm{b}$, and c) after the within-season calibration of the remote sensing-integrated barley model for cultivars seeded in autumn 2018 at Chonnam National University (CNU), Gwangju and for Heenchal seeded in autumn 2018 and in both autumn and spring 2019 at Gyeongsang National University (GNU), Jinju, south Gyeongsang province, South Korea.

\begin{tabular}{cccccccc}
\hline Site & Year & Season & Cultivar & $\mathbf{L}_{\mathbf{0}}$ & $\mathbf{a}$ & $\mathbf{b}$ & $\mathbf{c}$ \\
\hline CNU & 2018 & Autumn & Black & 0.0183 & 0.1667 & 0.00408 & 0.00069 \\
& & Autumn & Heenchal & 0.0048 & 0.0527 & 0.00703 & 0.00027 \\
& & Autumn & Hopum & 0.0063 & 0.0431 & 0.00951 & 0.00005 \\
& & Autumn & Saechal & 0.0057 & 0.0325 & 0.00892 & 0.00021 \\
\hline \multirow{2}{*}{ GNU } & 2018 & Autumn & Heenchal & 0.3652 & 0.0045 & 0.00099 & 0.00104 \\
& \multirow{2}{*}{2019} & Spring & Heenchal & 0.0276 & 0.0598 & 0.00537 & 0.00255 \\
& & Autumn & Heenchal & 0.5509 & 0.2429 & 0.00653 & 0.00010 \\
\hline
\end{tabular}

\section{References}

1. Martin, J.D.; Leonard, W.H.; Stamp, D.L.; Waldren, R.P. Principles of Field Crop Production, 4th ed.; Pearson: London, UK, 2005.

2. Nguyen, V.; Jeong, S.; Ko, J.; Ng, C.; Yeom, J. Mathematical integration of remotely-sensed information into a crop modelling process for mapping crop productivity. Remote Sens. 2019, 11, 2131. [CrossRef]

3. Thornley, J.H.; Johnson, I.R. Plant and Crop Modelling: A Mathematical Approach to Plant and Crop Physiology; Clarendon Press: Oxford, UK, 1990.

4. Campbell, J.B.; Wynne, R.H. Introduction to Remote Sensing; Guilford Press: New York, NY, USA, 2011.

5. Jeong, S.; Ko, J.; Yeom, J.M. Nationwide Projection of Rice Yield Using a Crop Model Integrated with Geostationary Satellite Imagery: A Case Study in South Korea. Remote Sens. 2018, 10, 1665. [CrossRef]

6. Ko, J.; Jeong, S.; Yeom, J.; Kim, H.; Ban, J.O.; Kim, H.Y. Simulation and mapping of rice growth and yield based on remote sensing. J. Appl. Remote Sens. 2015, 9, 096067. [CrossRef]

7. Ahuja, L.R.; Rojas, K.W.; Hanson, J.D.; Shaffer, M.J.; Ma, L. Root Zone Water Quality Model: Modeling Management Effects on Water Quality and Crop Production; Water Resources Publications, LLC: Highland Ranch, CO, USA, 2000 .

8. Jones, J.W.; Hoogenboom, G.; Porter, C.H.; Boote, K.J.; Batchelor, W.D.; Hunt, L.; Wilkens, P.W.; Singh, U.; Gijsman, A.J.; Ritchie, J.T. The DSSAT cropping system model. Eur. J. Agron. 2003, 18, 235-265. [CrossRef]

9. Maas, S.J. Parameterized model of gramineous crop growth: II. within-season simulation calibration. Agron. J. 1993, 85, 354-358. [CrossRef]

10. Doraiswamy, P.C.; Moulin, S.; Cook, P.W.; Stern, A. Crop yield assessment from remote sensing. Photogramm. Eng. Remote Sens. 2003, 69, 665-674. [CrossRef]

11. Moulin, S.; Bondeau, A.; Delecolle, R. Combining agricultural crop models and satellite observations: From field to regional scales. Int. J. Remote Sens. 1998, 19, 1021-1036. [CrossRef]

12. Bouman, B.A.M. Linking physical remote sensing models with crop growth simulation models, applied for sugar beet. Int. J. Remote Sens. 1992, 13, 2565-2581. [CrossRef]

13. Zarco-Tejada, P.J.; Ustin, S.L.; Whiting, M.L. Temporal and spatial relationships between within-field yield variability in cotton and high-spatial hyperspectral remote sensing imagery. Agron. J. 2005, 97, 641-653. [CrossRef]

14. Labus, M.P.; Nielsen, G.A.; Lawrence, R.L.; Engel, R.; Long, D.S. Wheat yield estimates using multi-temporal NDVI satellite imagery. Int. J. Remote Sens. 2002, 23, 4169-4180. [CrossRef]

15. Kern, A.; Barcza, Z.; Marjanović, H.; Árendás, T.; Fodor, N.; Bónis, P.; Bognár, P.; Lichtenberger, J. Statistical modelling of crop yield in Central Europe using climate data and remote sensing vegetation indices. Agric. For. Meteorol. 2018, 260-261, 300-320. [CrossRef]

16. Jeong, S.; Ko, J.; Choi, J.; Xue, W.; Yeom, J.M. Application of an unmanned aerial system for monitoring paddy productivity using the GRAMI-rice model. Int. J. Remote Sens. 2018, 39, 2441-2462. [CrossRef] 
17. Huang, Y.; Ryu, Y.; Jiang, C.; Kimm, H.; Kim, S.; Kang, M.; Shim, K. BESS-Rice: A remote sensing derived and biophysical process-based rice productivity simulation model. Agric. For. Meteorol. 2018, 256-257, 253-269. [CrossRef]

18. Cheng, Z.; Meng, J.H.; Wang, Y. Improving Spring Maize Yield Estimation at Field Scale by Assimilating Time-Series HJ-1 CCD Data into the WOFOST Model Using a New Method with Fast Algorithms. Remote Sens. 2016, 8, 303. [CrossRef]

19. Maas, S.J. GRAMI: A Crop Model Growth Model that Can Use Remotely Sensed Information; USDA-ARS: Washington, DC, USA, 1992; p. 78.

20. Maas, S.J. Parameterized model of gramineous crop growth: I. leaf area and dry mass simulation. Agron. J. 1993, 85, 348-353. [CrossRef]

21. Ko, J.; Maas, S.J.; Lascano, R.J.; Wanjura, D. Modification of the GRAMI model for cotton. Agron. J. 2005, $97,6$. [CrossRef]

22. Ko, J.; Maas, S.J.; Mauget, S.; Piccinni, G.; Wanjura, D. Modeling water-stressed cotton growth using within-season remote sensing data. Agron. J. 2006, 98, 1600-1609. [CrossRef]

23. Shawon, A.R.; Ko, J.; Ha, B.; Jeong, S.; Kim, D.K.; Kim, H.Y. Assessment of a Proximal Sensing-integrated Crop Model for Simulation of Soybean Growth and Yield. Remote Sens. 2020, 12, 410. [CrossRef]

24. Yeom, J.M.; Jeong, S.; Jeong, G.; Ng, C.T.; Deo, R.C.; Ko, J. Monitoring paddy productivity in North Korea employing geostationary satellite images integrated with GRAMI-rice model. Sci. Rep. 2018, 8, 16121. [CrossRef]

25. Jeong, S.; Ko, J.; Kang, M.; Yeom, J.; Ng, C.T.; Lee, S.H.; Lee, Y.G.; Kim, H.Y. Geographical variations in gross primary production and evapotranspiration of paddy rice in the Korean Peninsula. Sci. Total Environ. 2020, 714, 136632. [CrossRef]

26. Jeong, S.; Ko, J.; Kim, M.; Kim, J. Construction of an unmanned aerial vehicle remote sensing system for crop monitoring. J. Appl. Remote Sens. 2016, 10, 026027. [CrossRef]

27. Cai, Y.; Guan, K.; Nafziger, E.; Chowdhary, G.; Peng, B.; Jin, Z.; Wang, S.; Wang, S. Detecting In-Season Crop Nitrogen Stress of Corn for Field Trials Using UAV- and CubeSat-Based Multispectral Sensing. IEEE J. Sel. Top. Appl. Earth Obs. Remote Sens. 2019, 12, 5153-5166. [CrossRef]

28. Mesas-Carrascosa, F.J.; Torres-Sánchez, J.; Clavero-Rumbao, I.; García-Ferrer, A.; Peña, J.M.; Borra-Serrano, I.; López-Granados, F. Assessing Optimal Flight Parameters for Generating Accurate Multispectral Orthomosaicks by UAV to Support Site-Specific Crop Management. Remote Sens. 2015, 7, 12793-12814. [CrossRef]

29. Kobayashi, H.; Ryu, Y.; Baldocchi, D.D.; Welles, J.M.; Norman, J.M. On the correct estimation of gap fraction: How to remove scattered radiation in gap fraction measurements? Agric. For. Meteorol. 2013, 174-175, 170-183. [CrossRef]

30. Rouse, J.W., Jr.; Haas, R.H.; Schell, J.A.; Deering, D.W. Monitoring vegetation systems in the Great Plains with ERTS. In Proceedings of the NASA Goddard Space Flight Center 3d ERTS-1 Symp, Greenbelt, MD, USA, 1 January 1974; pp. 309-317.

31. Rondeaux, G.; Steven, M.; Baret, F. Optimization of soil-adjusted vegetation indices. Remote Sens. Environ. 1996, 55, 95-107. [CrossRef]

32. Haboudane, D.; Miller, J.R.; Pattey, E.; Zarco-Tejada, P.J.; Strachan, I.B. Hyperspectral vegetation indices and novel algorithms for predicting green LAI of crop canopies: Modeling and validation in the context of precision agriculture. Remote Sens. Environ. 2004, 90, 337-352. [CrossRef]

33. Roujean, J.L.; Breon, F.M. Estimating PAR absorbed by vegetation from bidirectional reflectance measurements. Remote Sens. Environ. 1995, 51, 375-384. [CrossRef]

34. Solberg, S.; Brunner, A.; Hanssen, K.H.; Lange, H.; Næsset, E.; Rautiainen, M.; Stenberg, P. Mapping LAI in a Norway spruce forest using airborne laser scanning. Remote Sens. Environ. 2009, 113, 2317-2327. [CrossRef]

35. Press, W.H.; Teukolsky, S.A.; Vetterling, W.T.; Flannery, B.P. Numerical Recipes: The Art of Scientific Computing; Cambridge University Press: New York, NY, USA, 1992.

36. Nash, J.C. Compact Numerical Methods for Computers: Linear Algebra and Function Minimisation; CRC Press: Adam Hilger, NY, USA, 1990.

37. Nash, J.E.; Sutcliffe, J.V. River flow forecasting through conceptual models part I-A discussion of principles. J. Hydrol. 1970, 10, 282-290. [CrossRef] 
38. Monteith, J.L. Climate and the efficiency of crop production in Britain. Phil. Trans. R. Soc. Lond. B 1977, 281, 277-294.

39. Goyne, P.; Milroy, S.; Lilley, J.; Hare, J. Radiation interception, radiation use efficiency and growth of barley cultivars. Aust. J. Agric. Res. 1993, 44, 1351-1366. [CrossRef]

40. Kemanian, A.R.; Stöckle, C.O.; Huggins, D.R. Variability of Barley Radiation-Use Efficiency. Crop Sci. 2004, 44, 1662-1672. [CrossRef]

41. Manderscheid, R.; Pacholski, A.; Frühauf, C.; Weigel, H.J. Effects of free air carbon dioxide enrichment and nitrogen supply on growth and yield of winter barley cultivated in a crop rotation. Field Crop. Res. 2009, 110, 185-196. [CrossRef]

42. Charles-Edwards, D.; Doley, D.; Rimmington, G.M. Modelling Plant Growth and Development; Academic Press: Cambridge, MA, USA, 1986.

43. Saeki, T. Light relations in plant communities. In Environmental Control of Plant Growth; Elsevier: Amsterdam, The Netherlands, 1963; pp. 79-94.

44. Monteith, J.L. Solar Radiation and Productivity in Tropical Ecosystems. J. Appl. Ecol. 1972, 9, 747-766. [CrossRef]

45. Szeicz, G.; Monteith, J.; Dos Santos, J. Tube solarimeter to measure radiation among plants. J. Appl. Ecol. 1964, 1, 169-174. [CrossRef]

46. Gunn, S.; Farrar, J.F.; Collis, B.E.; Nason, M. Specific leaf area in barley: Individual leaves versus whole plants. New Phytol. 1999, 143, 45-51. [CrossRef]

47. Pyankov, V.I.; Ivanova, L.A.; Lambers, H. Quantitative anatomy of photosynthetic tissues of plants species of different functional types in a boreal vegetation. In Inherent Variation in Plant Growth: Physiological Mechanisms and Ecological Consequences; Backhuys Publishers: Kerkwerve, The Netherlands, 1998; pp. 71-87.

48. Bendig, J.; Bolten, A.; Bennertz, S.; Broscheit, J.; Eichfuss, S.; Bareth, G. Estimating Biomass of Barley Using Crop Surface Models (CSMs) Derived from UAV-Based RGB Imaging. Remote Sens. 2014, 6, 10395-10412. [CrossRef]

49. Escalante, H.J.; Rodríguez-Sánchez, S.; Jiménez-Lizárraga, M.; Morales-Reyes, A.; de la Calleja, J.; Vazquez, R. Barley yield and fertilization analysis from UAV imagery: A deep learning approach. Int. J. Remote Sens. 2019, 40, 2493-2516. [CrossRef]

50. Peña, J.M.; Ostos-Garrido, F.J.; Torres-Sánchez, J.; Pistón, F.; Castro, A.I.d. A UAV-based system for monitoring crop growth in wheat, barley and triticale phenotyping field trials. In Proceedings of the 12th European Conference on Precision Agriculture, Celebrada in Montpellier, Montpellier, France, 8-11 July 2019.

Publisher's Note: MDPI stays neutral with regard to jurisdictional claims in published maps and institutional affiliations.

(C) 2020 by the authors. Licensee MDPI, Basel, Switzerland. This article is an open access article distributed under the terms and conditions of the Creative Commons Attribution (CC BY) license (http://creativecommons.org/licenses/by/4.0/). 